\title{
Protective effect of garlic extract against maternal and foetal cerebellar damage induced by lead administration during pregnancy in rats
}

\author{
H.A. Saleh11, G.S. Abd El-Aziz' ${ }^{1}$, H.N. Mustafa ${ }^{1}$, A.H.A. Saleh ${ }^{1}$, A.O. Mal², A.H.S. Deifalla ${ }^{3}$, \\ M. Aburas ${ }^{4}$ \\ ${ }^{1}$ Anatomy Department, Faculty of Medicine, King Abdulaziz University, Jeddah, Saudi Arabia \\ ${ }^{2}$ Marine Biology Department, Faculty of Marine Sciences, King Abdulaziz University, Jeddah, Saudi Arabia \\ ${ }^{3}$ Anatomy Department, Faculty of Medicine, Arabian Gulf University, Bahrain \\ ${ }^{4}$ Biological Sciences Department, Faculty of Sciences, King Abdulaziz University, Jeddah, Saudi Arabia \\ [Received: 21 May 2017; Accepted: 16 June 2017]
}

Background: In spite of its industrial usefulness and varied daily uses, lead $\mathrm{Pb}$ pollution is a widespread ecological problem that faces the humans in the $21^{\text {th }}$ century. $\mathrm{Pb}$ was found to produces a wide range of toxic effects including neurotoxicity especially to the developing and young offspring. Recently, the utilisation of herbal plants has received a significant attention where there has been rising awareness in their therapeutic use; among these is the garlic. In light of the above, the current study is designed experimentally in female pregnant rats in order to investigate the beneficial role of garlic extract in the protection from the maternal and foetal cerebellar damage produced by administration of different doses of $\mathrm{Pb}$ during pregnancy.

Materials and methods: Positively pregnant female rats were divided into five groups; one control group, two Pb-treated groups (exposed to 160 and $320 \mathrm{mg} / \mathrm{kg}$ b.w. of $P b$, respectively) and two groups treated with both $\mathrm{Pb}$ and garlic (exposed to $\mathrm{Pb}$ as previous groups together with $250 \mathrm{mg} / \mathrm{kg} \mathrm{b.w./day} \mathrm{of} \mathrm{garlic} \mathrm{extract).}$ Treatments started from day 1 to day 20 of pregnancy, where the mother rats of different experimental groups were sacrificed to obtain the foetuses. Pb level in the maternal and foetal blood and cerebellum was estimated by spectrophotometry. Specimens of the cerebellum of different mother and foetal groups were processed to histological and immunohistochemical staining for microscopic examination. Results: The results showed that administration of $\mathrm{Pb}$ to pregnant rats resulted in a dose-dependent toxicity for both mothers and foetuses in the form of decrease in maternal weight gain, placental and foetal weights, brain weight and diminished foetal growth parameters, which were prominent in rat's group treated with larger dose of $\mathrm{Pb}$. In Pb-treated rats, $\mathrm{Pb}$ level in blood and cerebellum was high when compared with the control group. The histopathological examination of the cerebellum of treated dams and foetuses showed marked alterations mainly in the form of Purkinje cell degeneration and lack of development of foetal cerebellum. Co-treatment of garlic extract along with $\mathrm{Pb}$ resulted in a significant decrease in $\mathrm{Pb}$ levels as compared with those treated with $\mathrm{Pb}$ alone with improvement of the histopathological changes.

Address for correspondence: Prof. H.A Saleh, MD, MPhil, PhD, Department of Anatomy, Faculty of Medicine, King Abdulaziz University, P.O. Box 80316, Jeddah 21589, Saudi Arabia, e-mail: hamidphd@hotmail.com 
Conclusions: This study was useful in evaluating the hazardous effects of uncontrolled use of $\mathrm{Pb}$ in general and in assessing the developmental and neurotoxicity of foetuses due to exposure during pregnancy in particular. Co-administration of garlic has beneficial effects in amelioration of Pb-induced neurotoxicity and reversing the histopathological changes of the cerebellum of mother rats and foetuses. (Folia Morphol 2018; 77, 1: 1-15)

Key words: lead, garlic, Purkinje cells, glial fibrillary acidic protein

\section{INTRODUCTION}

Lead $(\mathrm{Pb})$ is a common environmental and industrial pollutant that has been detected in all phases of environment and biological systems. $\mathrm{Pb}$ is a useful metal in life where it is used in many industries; however, it is considered as one of the most toxic heavy metals for humans and animals that affects various systems in the body [35]. Pb can enter body mainly via eating, drinking or inhalation, where its absorption occurs primarily in the gastrointestinal and respiratory systems and once ingested, it is carried in blood and transported to many tissues such as kidneys, liver, bones and brain [39].

Lead $(\mathrm{Pb})$ is known to be highly neurotoxic agent affecting both central and peripheral nervous systems. The effects on the peripheral nervous system are more pronounced in adults, while the central nervous system (CNS) is more prominently affected in children [31]. It was reported that the brain is a susceptible target to $\mathrm{Pb}$ toxicity because of its high myelin-associated content, which makes it vulnerable to peroxidative reactions resulting in myelin sheath fragmentation and reactive astrocytosis [36]. Moreover, $\mathrm{Pb}$ intoxication is considered as a potential factor in brain damage, mental impairment, behavioural abnormalities, neuromuscular weakness and impaired cognitive functions in experimental animals [44]. Also, it was reported that $\mathrm{Pb}$ can disrupt the main structural components of blood brain barrier by damaging endothelial, glial cell and affecting the formation of tight junctions between barrier cells [26].

Developmental toxicity of $\mathrm{Pb}$ has recently emerged as a potentially large public health problem for children and women of childbearing age because the foetus is particularly vulnerable to the environmental toxicants [18]. Prenatal $\mathrm{Pb}$ exposure produces toxic effects in the human foetus, including increased risk of preterm delivery, low birth weight, and impaired mental development, because during the period of early organogenesis, the onset of greatest susceptibility to teratogenesis occurs [14]. However, the greatest adverse effects are seen during the latest stages of brain development, suggesting that $\mathrm{Pb}$ may interfere with the apoptotic process and synaptic connections [30]. Also, in vivo and in vitro studies have shown that $\mathrm{Pb}$ may disrupt the blood-brain barrier by injuring astrocytes, with a secondary damage to the endothelial microvasculature [22].

Recently, there has been increased interest in the therapeutic potential of medicinal plants as antioxidants in reducing free radical-induced tissue injury as many synthetic antioxidants have been shown to have some side-effects [10]. Numerous herbal supplements have become increasingly popular in recent years; among these is the garlic [29]. Garlic (Allium sativum) is a versatile vegetable used as ingredients in many dishes for flavour and taste enhancement. Its active agent is allicin, which imparts its characteristic odour as well as medicinal properties [41]. Garlic is credited to have remarkable therapeutic and pharmacological properties, e.g. antimicrobial, antithrombotic, antihypertensive, antiatherosclerotic, antihyperglycaemic and anticancer [25]. Also, it is known that garlic acts as an antioxidant by enhancing cellular antioxidant enzymes and inhibits lipid peroxidation [40]. Also, many studies have reported the prophylactic efficacy of garlic extract in reducing the $\mathrm{Pb}$ burden from various tissues, e.g. liver, kidneys, blood and bone [37].

A lot of the useful health-associated features of garlic have been attributed to its main effective element organosulphur substance "allicin" (thio-2-propene-1-sulphinic acid S-allyl ester). Allicin is produced during the crushing of garlic by means of the reaction of alliin, a non-protein amino acid, along with the pyridoxal phosphate-containing enzyme, alliinase $[25,40]$.

In the view of the above, the present study was designed experimentally in female rats in order to investigate the neuroprotective role of garlic extract in the protection from the maternal and foetal cerebellar damage produced by $\mathrm{Pb}$ administration during pregnancy. 


\section{MATERIALS AND METHODS}

\section{Ethical approval}

This study was conducted after approval by the Medical Research Ethics Committee of the Faculty of Medicine, King Abdulaziz University, Jeddah, Saudi Arabia, which is in accordance with the guidelines of the National Institute of Health Guide (National Institute of Health Publications No. 80-23, Revised 1978) for the care and use of Laboratory Animals for experimental procedure.

\section{Chemicals}

Lead acetate (PbAc) pure crystals with molecular weight of 379.33, Sigma-Aldrich Chemicals Co. (St. Louis, Missouri, USA) and other chemicals and staining reagents used in this study were purchased through local scientific agents in Jeddah.

\section{Preparation of garlic extract}

Garlic was purchased from local markets in Jeddah. Aqueous garlic extract was prepared according to the method used by Ide and Lau [21]. Briefly, fresh garlic bulbs were separated, peeled and washed with distilled water. After drying in a shed, the clean garlic bulbs were crushed with an electric grinder. The homogenate was centrifuged in cold at 3,000 rpm for 5 min to remove any debris and the extract was decanted carefully through muslin cloth.

\section{Animals and experimental work}

Adult, sexually mature nulliparous female SpragueDawley albino rats (weighing 200-225 g at the beginning of the experiment) were used in this study. They were obtained from the Animal House of King Fahd Medical Research Centre (KFMDC). This study was approved and registered by the Committee of Animal Investigations, Faculty of Medicine, King Abdulaziz University. During the study, the female rats were kept in separate metallic cages under standard temperature $\left(24 \pm 2^{\circ} \mathrm{C}\right)$, humidity $(55 \pm 5 \%)$ and lighting (12 h:12 h, light:dark) conditions. They were fed a standard chow diet ad libitum and had free access to water. Mating procedure was assisted by placing the individual females overnight in the home cage of a singly-housed male of the same stock. Gestation was confirmed by positive identification of spermatozoa in a vaginal lavage smear and is designated as gestation day 0 (GD0) with subsequent days of gestation were numbered accordingly [3]. Positively pregnant females were only chosen and randomly divided into the following five (8 rats) groups:
- Group I - the female rats were treated with deionised water only from GD 1-20 of pregnancy (control group);

- Group II (L160) - the female rats were given $160 \mathrm{ppm}$ of $\mathrm{Pb}$ acetate $(\mathrm{PbAc})$ through oral gavage once a day from GD 1-20 of pregnancy;

- Group III (L160+garlic) - the female rats were given $160 \mathrm{ppm}$ of PbAc plus garlic extract (250 mg/kg b.w.) by oral gavage once a day from GD 1-20 of pregnancy;

- Group IV (L320) - the female rats were given 320 ppm of PbAc by oral gavage from GD 1-20 of pregnancy;

- Group V (L320+garlic) - the female rats were given $320 \mathrm{ppm}$ of $\mathrm{PbAc}$ plus garlic extract (250 mg/kg b.w.) by oral gavage once a day from GD 1-20 of pregnancy.

$\mathrm{Pb}$ solution was prepared by dissolving $\mathrm{PbAc}$ in acidified distilled water in concentrations of 0.1 and $0.2 \%(\mathrm{w} / \mathrm{v})$, containing 160 and $320 \mathrm{ppm}$ of $\mathrm{Pb}$ respectively [45]. The PbAc solution was prepared every 2 days to minimise the $\mathrm{Pb}$ precipitates [13].

\section{Evaluations of pregnant rats and foetuses}

The pregnant female rats of each group were daily observed throughout gestation for mortality and morbidity and body weight gain following treatment. On day 20 of gestation, under ether anaesthesia, blood samples were collected from pregnant rats of different groups and centrifuged at $3000 \mathrm{rpm}$ for $15 \mathrm{~min}$ to separate the sera which were stored at $-80^{\circ} \mathrm{C}$. Then, the abdominal cavity was opened and the full extent of both uterine horns was exposed where the foetal position and number of live and dead foetuses were recorded. Then, the foetuses and placentas were gently removed and weighted separately. The heads of mother rats and foetuses of different groups were opened where the cerebellum of mother rats and foetal brains were quickly extracted and weighed. All extracted specimens were divided sagittally into two halves; the right halves were fixed in $10 \%$ neutral buffer formalin for histological and immunohistochemical study and left halves were frozen and stored at $-70^{\circ} \mathrm{C}$.

\section{Measurement of $\mathrm{Pb}$ levels in the blood and brain tissues}

The collected blood samples from female mother rats as well as cord blood of different experimental 
groups were added to $\mathrm{HNO}_{3}$ Suprapur (E. Merck), centrifuged at 15,000 rpm for $15 \mathrm{~min}$, and aliquots were taken from the clear solution and diluted $(1: 5 \mathrm{v} / \mathrm{v})$ with deionised water. The left halves of the cerebellum from rat mothers and whole brain of foetuses and placenta of different groups were carefully weighed and placed in the polypropylene tubes and digested in $1 \mathrm{~mL}$ of concentrated $\mathrm{HNO}_{3}$ Suprapur in a shaking water bath at $60^{\circ} \mathrm{C}$ for $30 \mathrm{~min}$. This led to homogeneous dispensing of brain tissues in semisolid form, which enables the analysis of $\mathrm{Pb}$ even if complete destruction of organic matter is not there [45]. After digestion, aliquots were taken from the clear solution and diluted $(1: 5 \mathrm{v} / \mathrm{v})$ with deionised water. $\mathrm{Pb}$ levels were measured using graphite furnace atomic absorption spectrophotometer (GFASS, Perkin-Elmer Model 3030) at King Fahd Medical Research Centre, King Abdulaziz University. Results were expressed as $\mu \mathrm{g}$ of $\mathrm{Pb} / \mathrm{dL}$ blood and $\mathrm{Pb}$ in brain and placenta was expressed as $\mu \mathrm{g} / \mathrm{g}$ tissue weight.

\section{Histological and immunohistochemical methods}

The fixed right halves of the maternal and foetal brains of different experimental groups were dehydrated, cleared and embedded in paraffin and then sections of $5 \mu \mathrm{m}$ thickness were cut. Some sections were stained with haematoxylin-eosin (H\&E) for general examination [34]. Other sections were immunohistochemically stained with modified avidin-biotin peroxidase technique for anti-glial fibrillary acidic protein (GFAP) to examine the astrocytes. Briefly, deparaffinised and rehydrated sections were treated with $0.01 \mathrm{M}$ citrate buffer ( $\mathrm{pH} \mathrm{6.0)}$ for $10 \mathrm{~min}$ to unmask antigen and then incubated with a monoclonal antibody against GFAP (1:100 monoclonal mouse anti GFAP) (purchased from DAKO Agilent Technologies Company, Sigma, St. Louis, Missouri, USA) for 18-20 h. This stain is specific for the intermediated filaments fibrillary acidic protein found in astrocytes and not found in nerve cells and even other types of glial cells, such as microglia or oligodendroglia. Detection of the antibody was carried out using a biotin-streptavidin detection system with $0.05 \%$ diaminobenzidine as a chromogen (Amersham, Little Chalfont, UK) and counterstaining was done with haematoxylin [32]. GFAP positive cells appeared brown and nuclei appeared blue. The positive results were indicated by brown coloration of the cell membrane and cytoplasm of the astrocytes [33]. Finally, all slides were examined with an Olympus BX53 microscope equipped with camera (Olympus, Tokyo, Japan) at different magnifications.

\section{Statistical analysis}

All the data were presented as mean \pm standard deviation of studied parameters from different groups. Data were analysed using a one-way analysis of variance (ANOVA) followed by Bonferroni's post hoc test or Student's t-test, wherever applicable. All statistical analyses were done using the Statistical Package for the Social Sciences (SPSS, USA). The values of $p<0.05$ were considered significant.

\section{RESULTS}

\section{Maternal findings}

In general, during the experiment, no pregnant female were aborted or died and there was no effect of the treatment on the duration of pregnancy. As represented in Table 1 and Graph 1, there was a significant reduction in both maternal weight gain and placental and cerebellum weights in $\mathrm{Pb}$-treated groups when compared with the control group, which was more marked in larger $\mathrm{Pb}$ dose. Also, it was noticed that the co-administration of garlic extract improved this effect.

\section{Foetal findings}

As seen in Table 2 and Graph 2, the Pb-treated groups displayed a reduction of foetal weight as well as brain weight when compared with the control group, which was more marked in larger $\mathrm{Pb}$ dose; and the co-administration of garlic extract along with $\mathrm{Pb}$ improved these effects.

\section{Maternofoetal lead analysis}

The data in Table 3 and Graph 3 showed that there were parallel and significant increases in the mean values of $\mathrm{Pb}$ concentrations in the maternal blood and cerebellum, placenta and foetal brain in $\mathrm{Pb}$ treated groups when compared with control group; being higher in larger $\mathrm{Pb}$ dose. Also, co-administration of garlic extract along with $\mathrm{Pb}$ resulted again in reduction in $\mathrm{Pb}$ levels in these organs towards the control values. Analysis showed that $\mathrm{Pb}$ content in foetal brain was positively correlated with placental $\mathrm{Pb}$ level, which indicates the role of the placenta in $\mathrm{Pb}$ transfer to the foetus.

\section{Histological results}

Examination of cerebellar cortex from mother rats of the control and garlic treated groups (Fig. 1) pro- 
Table 1. Effect of gestational lead $(\mathrm{Pb})$ and garlic administration on some parameters of pregnant rats (mean \pm standard deviation)

\begin{tabular}{|c|c|c|c|}
\hline Groups & Maternal weight gain [g] & Placental weight [g] & Cerebellum weight [g] \\
\hline Control (8) & $99.6 \pm 11.9$ & $0.69 \pm 0.01$ & $0.38 \pm 0.09$ \\
\hline L160 (8) & $83.6 \pm 12.9^{b, d}$ & $0.62 \pm 0.012^{b, d}$ & $0.32 \pm 0.11^{b, d}$ \\
\hline L160 + garlic (8) & $92.6 \pm 7.83^{\mathrm{a}}$ & $0.66 \pm 0.09$ a & $0.36 \pm 0.08^{a}$ \\
\hline L320 (8) & $75.0 \pm 6.93^{c, e}$ & $0.55 \pm 0.08^{c, e}$ & $0.29 \pm 0.07^{c, e}$ \\
\hline L320 + garlic (8) & $85.6 \pm 7.12^{b}$ & $0.62 \pm 0.08^{b}$ & $0.34 \pm 0.12^{b}$ \\
\hline
\end{tabular}

ANOVA test with Bonferroni post-hoc test: ap $<0.01$ compared with control group; ${ }^{\mathrm{P}} \mathrm{P}<0.001$ compared with control; ${ }^{\mathrm{c} P}<0.0001$ compared with control; ${ }^{\mathrm{d} P}<0.01$ compared with L160 group, eP $<0.01$ compared with L160 + garlic group

Table 2. Effect of gestational lead $(\mathrm{Pb})$ and garlic administration on foetal weight and brain weight (mean \pm standard deviation)

\begin{tabular}{lcc}
\hline Groups & Foetal weight [g] & Foetal brain weight [g] \\
\hline Control (159) & $2.75 \pm 0.029$ & $0.128 \pm 0.09$ \\
L160 (148) & $2.33 \pm 0.043^{\mathrm{b}, \mathrm{d}}$ & $0.111 \pm 0.08^{\mathrm{b}, \mathrm{d}}$ \\
L160 + garlic (151) & $2.43 \pm 0.049^{\mathrm{a}}$ & $0.118^{\mathrm{a}} \pm 0.09^{\mathrm{a}}$ \\
L320 (127) & $2.1 \pm 0.042^{\mathrm{c}, \mathrm{e}}$ & $0.101 \pm 0.07^{\mathrm{c}, \mathrm{e}}$ \\
L320 + garlic (144) & $2.36 \pm 0.045^{\mathrm{b}}$ & $0.113^{\mathrm{b}} \pm 0.08^{\mathrm{b}}$ \\
\hline
\end{tabular}

ANOVA test with Bonferroni post-hoc test: ap $<0.01$ compared with control group; $\mathrm{bP}<0.001$ compared with control; $\mathrm{cP}<0.0001$ compared with control; ${ }^{\mathrm{d} P}<0.01$ compared with L160 group; $\mathrm{eP}<0.01$ compared with L160 + garlic group

Table 3. Effect of gestational lead $(\mathrm{Pb})$ and garlic administration on maternofoetal $\mathrm{Pb}$ concentrations (mean \pm standard deviation)

\begin{tabular}{|c|c|c|c|c|}
\hline Groups & $\begin{array}{c}\text { Maternal blood Pb level } \\
{[\mu \mathrm{g} / \mathrm{dL}]}\end{array}$ & $\begin{array}{c}\text { Maternal cerebellum } \\
\mathrm{Pb} \text { level }[\mu \mathrm{g} / \mathrm{g} \text { of tissues] }\end{array}$ & $\begin{array}{l}\text { Placental Pb level } \\
{[\mu \mathrm{g} / \mathrm{g} \text { of tissues] }}\end{array}$ & $\begin{array}{c}\text { Foetal brain Pb level } \\
{[\mu \mathrm{g} / \mathrm{g} \text { of tissues] }}\end{array}$ \\
\hline Control & $5.1 \pm 1.1$ & $0.06 \pm 0.04$ & $0.08 \pm 0.009$ & $0.01 \pm 0.009$ \\
\hline L160 & $27.7 \pm 4.9^{\mathrm{b}, \mathrm{d}}$ & $1.05 \pm 0.13^{b, d}$ & $0.65 \pm 0.09^{b, d}$ & $0.44 \pm 0.11^{b, d}$ \\
\hline L160 + garlic & $11.1 \pm 4.5^{\mathrm{a}}$ & $0.29 \pm 0.17^{a}$ & $0.29 \pm 0.07^{a}$ & $0.19 \pm 0.09 a$ \\
\hline L320 & $41.5 \pm 7.1^{\mathrm{c}, \mathrm{e}}$ & $1.60 \pm 0.32^{c}$ & $1.86 \pm 0.21^{c}$ & $0.95 \pm 0.12^{c}$ \\
\hline L320 + garlic & $24.2 \pm 5.4^{b}$ & $0.33 \pm 0.21^{b}$ & $0.69 \pm 0.1^{b}$ & $0.59 \pm 0.14^{b}$ \\
\hline
\end{tabular}

ANOVA test with Bonferroni post-hoc test: ap $<0.01$ compared with control group; ; $P<0.001$ compared with control; $\mathrm{cP}<0.0001$ compared with control; ip $<0.01$ compared with $\mathrm{L} 160$ group; ${ }^{\mathrm{eP}}<0.01$ compared with $\mathrm{L} 160+$ garlic group

duced the same histological and immunohistochemical findings. In general, the normal architecture in the form of folia covered by a layer of pia matter was shown. Each folium contained a central core of white matter covered by an outer cortical grey matter; the cerebellar cortex, which was composed of three layers: an outer molecular layer (ML), a middle Purkinje cell layer (PL) and an inner granular cell layer. The molecular layer contained nerve fibres and few cells in the form of superficially located small stellate cells and deeper basket cells. The Purkinje cell layer was composed of a single row of cells along the outer margin of the granular layer. These cells have a large flask shaped cell body with apical dendrites that were arborising into the overlying molecular layer and they have basophilic granular cytoplasm and large vesicular central nucleus with prominent nucleolus. The granular layer was composed of clusters of small packed rounded cells with deeply stained nuclei that separated by small acidophilic areas. Immunohistochemical staining showed GFAP positive astrocytes; they appeared small with thin few processes in the granular and molecular layers.

Examination of cerebellar cortex of rats from Pb-treated groups (Figs. 2 and 3) showed that the most affected layer was the PL. In low dose Pb-treated group, there was irregular arrangement and wide 
A

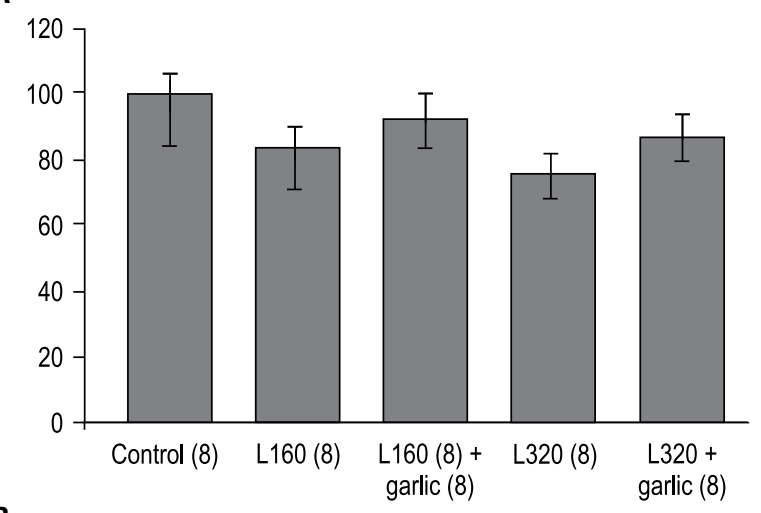

B

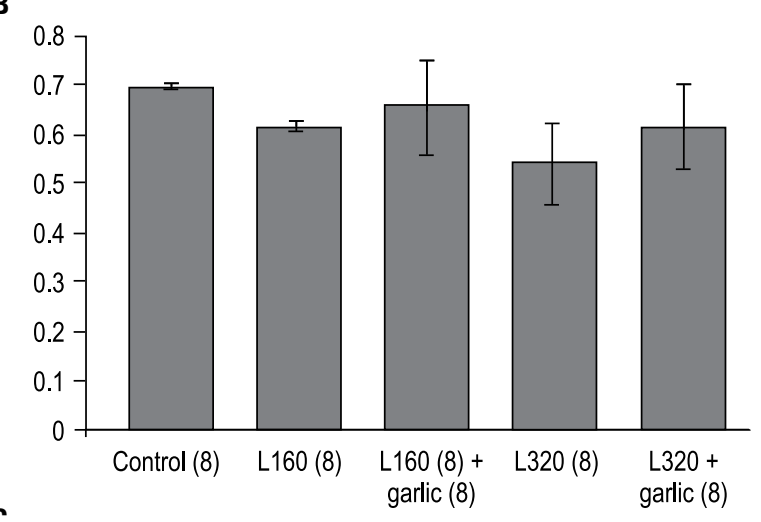

C

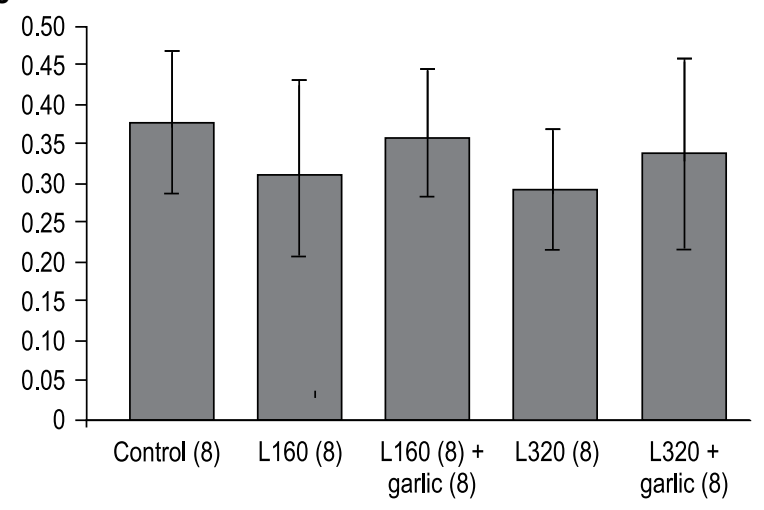

Graph 1. Effect of gestational lead $(\mathrm{Pb})$ and garlic administration on some parameters of pregnant rats (mean \pm standard deviation); A. Maternal weight gain [g]; B. Placental weight [g]; C. Cerebellum weight [g].

separation between Purkinje cells with distortion in their shape and diminished dendrites into the outer molecular layer compared with the control group. However, other neurons including granular cells were spared. In high dose $\mathrm{Pb}$-treated group, there was worse picture of PL compared to the control and $160 \mathrm{mg}$ Pb-treated groups, where there was apparent decrease in the number of Purkinje cells with some cells were fallen off leaving empty spaces while other cells appeared shrunken with a darkly stained cytoplasm and hardly identified nuclei. Also in some
A
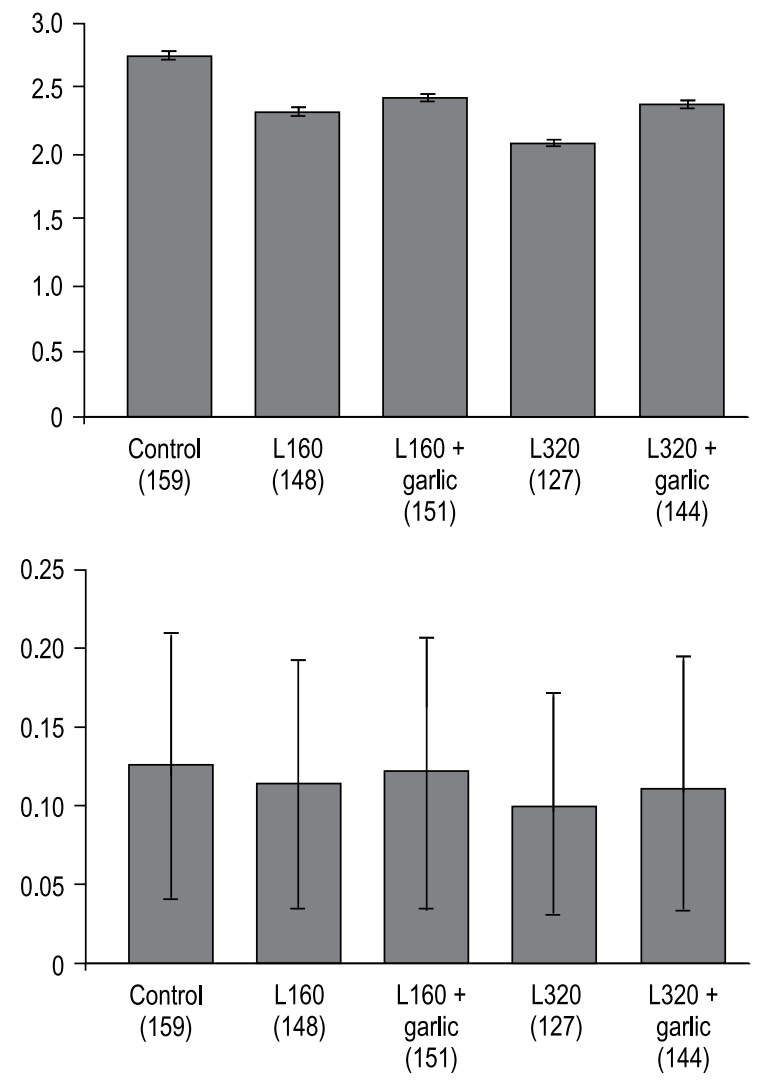

Graph 2. Effect of gestational lead $(\mathrm{Pb})$ and garlic administration on foetal weight and brain weight (mean \pm standard deviation); A. Foetal weight $[\mathrm{g}]$; B. Foetal brain weight [m].

Purkinje cells, the nuclei appeared irregular and dark with empty spaces around them or irregular, shrunken Purkinje cells with eosinophilic cytoplasm with surrounding perineuronal vacuolation (spongiosis of the neuropil) were seen. Moreover, some Purkinje cells showed eccentrically located nuclei, others showed pyknotic nuclei, karyorrhexis or even karyolysis. Immunohistochemical staining showed GFAP-positive astrocytes that were more abundant and appeared larger in the three cerebellar cortical layers. This was more obvious in the high dose $\mathrm{Pb}$-treated group.

Examination of cerebellar cortex of rats of $\mathrm{Pb}$ and garlic treated groups (Fig. 4) showed monolayer arrangement of Purkinje cells with mild disorganisation. Most of Purkinje cells appeared normal, while occasional cells were still shrunken and deeply stained. Some of them were surrounded by vacuolated cytoplasm. The molecular and granular layers were more or less similar to the control. Some cells showed a slightly elongated appearance. Immunohistochemical staining for GFAP showed that GFAP-positive astrocytes that were more 
A

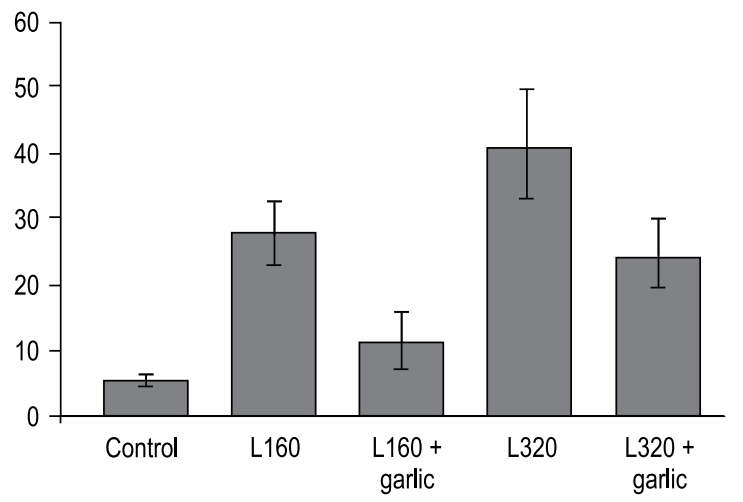

C

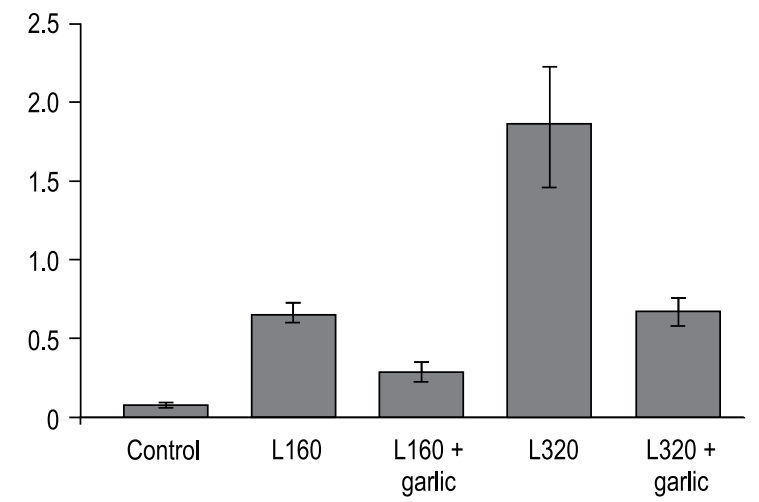

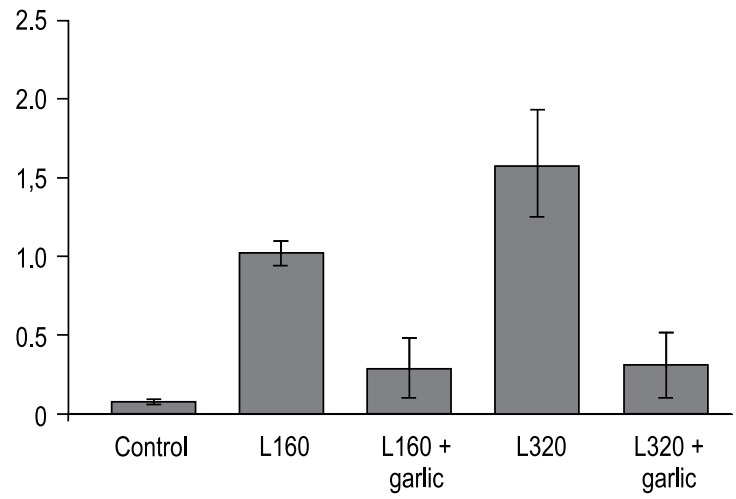

D

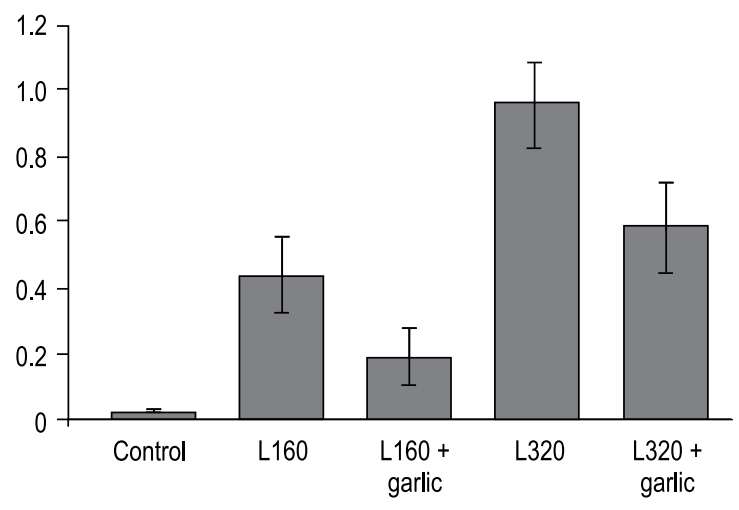

Graph 3. Effect of gestational lead $(\mathrm{Pb})$ and garlic administration on maternofoetal $\mathrm{Pb}$ concentrations (mean \pm standard deviation); $\mathbf{A}$. Maternal blood Pb level $[\mu \mathrm{g} / \mathrm{dL}]$; B. Maternal cerebellum Pb level $[\mu \mathrm{g} / \mathrm{g}$ of tissues]; C. Placental Pb level $[\mu \mathrm{g} / \mathrm{g}$ of tissues]; D. Foetal brain Pb level in $[\mu \mathrm{g} / \mathrm{g}$ of tissues].

abundant and appeared larger in the three cerebellar cortical layers.

Examination of foetal brains at GD20 from the control as well as garlic treated groups (Fig. 5) showed nearly the same histological and immunohistochemical findings, where the developing cerebellum at this foetal stage was formed of a solid mass present in the dorsal part of the hindbrain without showing any foliation or fissures. The primitive cerebellum showed normal cellular architecture which consisted from outside inwards of three main layers: external granular layer (EGL) and Purkinje cell layer (PL) and a molecular layer (ML). The EGL was formed of densely aggregated neuroepithelial cells (bordering the lateral recess of the fourth ventricle and considered as the germinal zone of the cerebellum), which were oval or rounded in shape with darkly stained nuclei. The ML was relatively thick layer with deeply stained cells of different shape and size. The PCL was formed of several-cell-thick layers progressively lining up beneath the spreading EGL and could be observed mixed together with the underlying cells of ML. The immunohistochemical examination of GFAP-stained sections of foetal cerebellum demonstrated either negative or very little GFAP positive cellular reaction, which were scattered in the superficial layers of the EGL.

Examination of foetal brains at GD20 from the Pb-treated groups (Fig. 6) showed variable degrees of histopathological changes. In general, in low dose $\mathrm{Pb}$-treated group the picture did not differ from that of the control group. However, in foetuses from the high dose $\mathrm{Pb}$-treated group, there was a decrease in the size of primitive cerebellum as compared with the control. The cerebellar cortex showed apparent dispersion of its layers with the presence of cavitations and extracellular oedema. The EGL was thin in comparison to the control; its cells had small, rounded and deeply stained nuclei. The primitive PCL showed degeneration and loss the architecture, with diffusely distributed cells that failed to establish the typical monolayer; few of them were shrunken and deeply stained. The examination of GFAP-stained sections of foetal brain 

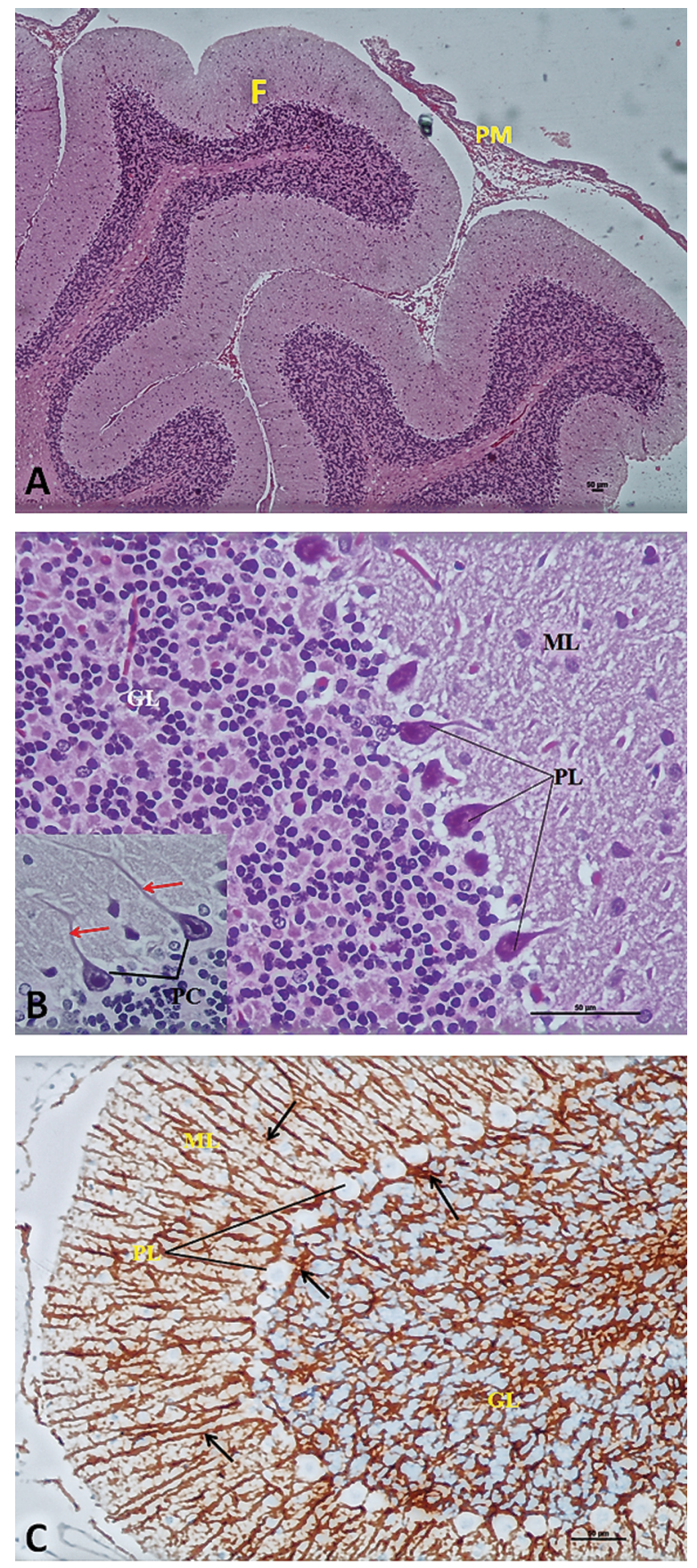

Figure 1. Photomicrographs of cerebellar cortex from control mother rats showing (A) normal architecture in the form of folia $(F)$ covered by a layer of pia matter (PM); B. Three layers of the cerebellar cortex from outside to inside; the outer molecular layer (ML) with relatively few cells, Purkinje cell layer (PL) which is formed of one layer of Purkinje cells (PC), and the inner granular cell layer $(G L)$ formed of tightly packed small granular cells $(\rightarrow)$. Inset showing large flask shaped Purkinje cells (PC) with basophilic granular cytoplasm and vesicular nuclei and apical dendrites arborizing into the molecular layer (red arrow); C. Immunohistochemical staining of glial fibrillary acidic protein (GFAP) revealed GFAP-positive staining in the astrocytes, which appear small with few processes ( $\downarrow)$ in the GL and ML layers. A: haematoxylin-eosin (H\&E) $\times 100, B: \times 400$, C: GFAP $\times 400$. from high dose Al-treated group showed an apparent increase in the GFAP positive immunoreactivity in the $E G L$ and $M L$ as compared to the control group.

Examination of foetal brains at GD20 from Pb- and garlic-treated groups (Fig. 7) showed a picture more or less similar to that of the control group regarding the cerebellar size and EGL thickness. Similarly, the appearance of migrating cells through the molecular layer of the developing cerebellar cortex was the same as in control foetuses. Also, the Purkinje cells were seen lining up beneath the spreading EGL and could be observed mixed together with the underlying cells of ML. The immunohistochemical examination of GFAP-stained sections of foetal cerebellum from this group showed reduction in the number of GFAP immunoreactive astrocytes.

\section{DISCUSSION}

Up till now, the $\mathrm{Pb}$ toxicity still is a major environmental health problem especially for children and pregnant women [2]. However, the effects of $\mathrm{Pb}$ on pregnancy and the foetus are complex and incompletely understood. Both mother and foetus could be affected by $\mathrm{Pb}$ exposure, with harmful acute and prolonged consequences. $\mathrm{Pb}$ crosses the placenta where there is a high correlation between maternal and umbilical cord blood $\mathrm{Pb}$ levels, thus exposing the foetus to increased risk of neurotoxicity [7]. Also, it is worthy to mention that, $\mathrm{Pb}$ exposure during gestation and early childhood has been reported to cause a variety of toxic effects in both human and animals [7, 26].

In this regard, pregnant women are at increased risk of $\mathrm{Pb}$ exposure to their foetus, where there are clear evidences indicating that $\mathrm{Pb}$ exposure during pregnancy has strong association to impairment of cognitive, behavioural development and neuromuscular functions [19]. Foetuses and young children are especially vulnerable to the neurological effects of $\mathrm{Pb}$, as the brain is in a state of intense cellular proliferation and rapid growth and because of the immaturity of blood-brain barrier which leads to greater absorption of $\mathrm{Pb}$ [26].

In the present study, the oral $\mathrm{Pb}$ administration to female rats at a dose of 160 and $320 \mathrm{mg} / \mathrm{kg}$ b.w. during pregnancy induced significant decrease in the body weight gain and brain/body weight ratio and foetal body weight when compared with control animals, which was dose-dependent. These results were explained by the fact that $\mathrm{Pb}$ induces reduction of food 

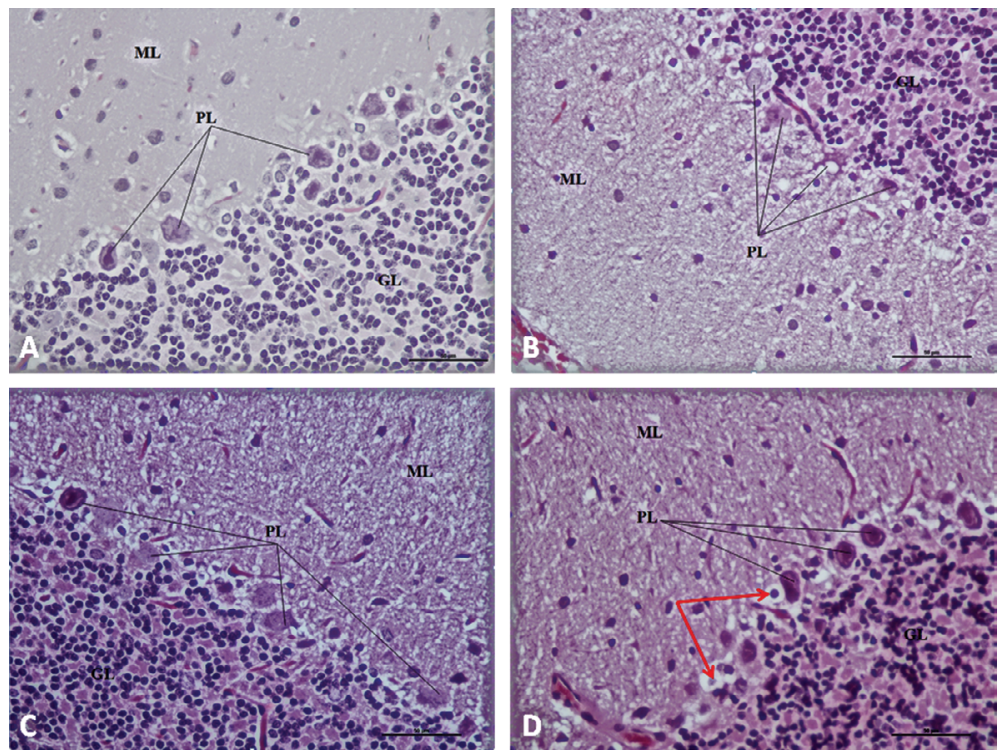

Figure 2. Photomicrographs of the cerebellar cortex from Pb-treated groups of mother rats showing $(\mathbf{A})$ wide separation between Purkinje cells $(\mathrm{P})$ with distortion in their shape and diminished dendrites into the outer molecular layer (ML) [L160 group]; B. Irregular arrangement of Purkinje cells (P), distortion in their shape and wide separation between them and diminished dendrites into the outer molecular layer (ML) [L320 group]; C. Irregular arrangement and distorted shape of Purkinje cells (P) with diminished cytoplasmic staining [L320 group]; D. Marked decrease in the number of Purkinje cells (P), with some cells are fallen off leaving empty spaces, and a few of them with an homogenised cytoplasm and darkly stained nuclei ( $\nabla$ ) or even vacuolated cytoplasm and pyknotic nuclei (red arrow) [L320 group]. A B, C, D: haematoxylin-eosin (H\&E) $\times 400$.

intake [5]. Similar observations have been reported by Zhang et al. [46] who mentioned that rats treated with $\mathrm{Pb}$ acetate $1 \mathrm{~g} / \mathrm{L}$ drinking water for 8 weeks displayed a significant decrease in body weight compared with the control group. Also Afifi and Embaby [4] reported that $\mathrm{Pb}$ produced a statistically significant decrease in the weight of the pups and their brain at post-natal days 0 and 21 of dams who consumed drinking water containing $300 \mathrm{mg} / \mathrm{L} \mathrm{Pb}$ [15].

The current results showed significantly elevated maternal blood $\mathrm{Pb}$ levels of the $\mathrm{Pb}$-treated groups, which was more significant in higher dose of $\mathrm{Pb}$. Parallel to these results, a previous study of Attia et al. [6] revealed that $\mathrm{Pb}$ blood level of adult mice administered $0.5 \% \mathrm{~Pb}$ acetate solution in drinking fluid for 30 days was $100-125 \mu \mathrm{g} / \mathrm{dL}$, which is a clinically toxic level. The current investigation showed that there is a correlation between maternal and umbilical cord blood $\mathrm{Pb}$ levels; these results strengthen the idea that $\mathrm{Pb}$ could freely cross through the placenta in a dose-response manner. It was reported that the placenta cannot prevent the foetus from exposure to $\mathrm{Pb}$, as this metal is able to cross the placental barrier easily [16]. Our results also are in line with study of Wang and Wang [see 8] that compared the umbilical cord blood $\mathrm{Pb}$ and maternal blood $\mathrm{Pb}$ levels and with previous studies which showed that the newborn infants' blood $\mathrm{Pb}$ was reflection to that of the mother [38]. Results from the present research indicate that dam $\mathrm{Pb}$ exposure not only produced an increase in $\mathrm{Pb}$ in foetus blood and placenta, but it also elevated the $\mathrm{Pb}$ in the brain of the developing foetus [11]. In accordance, previous studies indicated that $\mathrm{Pb}$ was highly concentrated in brain, placenta and umbilical cord and it was believed that $\mathrm{Pb}$ level in the placenta and umbilical cord could be good biomarkers of foetal $\mathrm{Pb}$ exposure [45].

It was reported that the toxic effects of $\mathrm{Pb}$ on the foetal brain are probably the most important and thoroughly studied consequence of intrauterine $\mathrm{Pb}$ exposure. This detrimental effect of even mildly elevated $\mathrm{Pb}$ levels has been well documented [11]. Also, in accordance, some other studies mentioned that the foetuses from pregnant rats exposed to low $\mathrm{Pb}$ level $(0.01 \%$ and $0.05 \% \mathrm{w} / \mathrm{v}$ orally for 45 days) displayed higher foetal brain Pb levels [37].

Histopathologically, in the present study, there was various degrees of structural damage of the maternal and foetal cerebellum of $\mathrm{Pb}$ treated groups, which was more obvious in high dose of $\mathrm{Pb}$. The cerebellum is one of the first structures of the brain to differentiate; however, it achieves its 

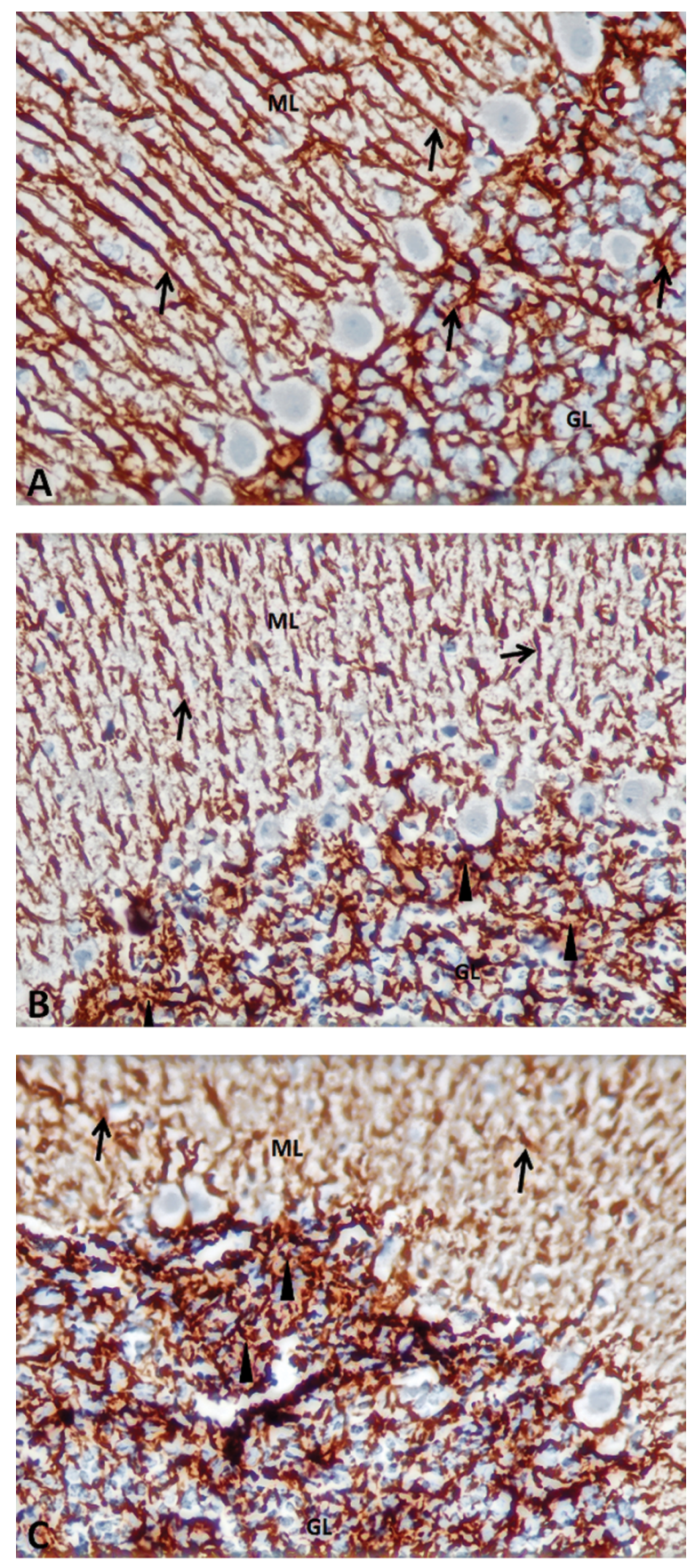

Figure 3. Photomicrographs of immunohistochemical staining of glial fibrillary acidic protein (GFAP) of the cerebellar cortex from $\mathrm{Pb}$-treated groups of mother rats showing (A) positive staining of astrocytes $(\downarrow)$, which appear greater in number with abundant distribution in the granular (GL) and molecular (ML) [L160 group]; B, C. Apparent increase and strong brown positive staining in the astrocytes especially in the deep part of the molecular layer (ML), granular layer (GL) and around the Purkinje cells $(\mathrm{P})$. This staining was more profound than in previous group [L320 group]. A, B, C: GFAP $\times 400$.

mature configuration many months after birth. For this reason, the cerebellum is especially vulnerable to developmental damages on exposure to oxidative stress $[12,20,23,28,42]$.
Our results were consistent with the previous findings of Iciek et al. [22] who reported cerebellar cortical damage including diffuse vacuolar degeneration, degeneration of the cerebellar Purkinje cells and cell loss after exposure to high levels of $\mathrm{Pb}$. The loss of Purkinje cells was evidenced by decrease in their numbers as shown by our morphometric data. Morphological changes observed in cerebellar tissue in the present study are supported by previous findings which showed changes in the cerebral cortex following $\mathrm{Pb}$ exposure [38]. Also, previous studies have indicated that $\mathrm{Pb}$ can be highly concentrated in the brain, placenta, and umbilical cord [45]; however, the cerebellum seems to be the preferable site for $\mathrm{Pb}$ deposition, causing neurotoxicity and cellular damage. This has been seen in a number of animals in the form of lack of stability and balance, tremors, gait disturbances and muscle weakness [27], which was explained on the basis of selective architectural alterations within the Purkinje cells attributed to their degenerative process [8]. It is known that the Purkinje cells are the predominant output regulator of the cerebellar cortex [4].

Our study showed that intrauterine $\mathrm{Pb}$ exposure revealed degeneration and reduced differentiation of the cerebellar cortex. In accordance to our results, it was reported the intrauterine exposure to $\mathrm{Pb}$ adversely affects cellular proliferation and differentiation and synaptic growth of the brain. Foetal exposure to $\mathrm{Pb}$ may also result in mental retardation, movement disorders, and renal dysfunction [9]. Also, in accordance, some studies have reported that $\mathrm{Pb}$ exposure during embryonic development induces cortical and cerebellar damage in newborn rats and in the developing rat hippocampus. These effects may well be indicative of foetal abnormalities, as $\mathrm{Pb}$ interferes with various proliferative and apoptotic pathways [16].

In the present study, increased GFAP-positive astrocytes were found in the maternal brains of $\mathrm{Pb}$ treated groups as compared with the control animals. In accordance, some studies have described an elevated GFAP content in various regions of the brain tissue after $\mathrm{Pb}$ exposure, which was mainly in the hippocampus and the cerebellar cortex. Accordingly, the determination of GFAP expression could possibly be a suitable marker to figure out neurodegenerative alterations [17]. It was reported that the developed gliosis in the Pb-treated rats could be caused by the creation of free radicals and antioxidants may minimise such a reactive gliosis, probably through reduction of the hazardous impact of 

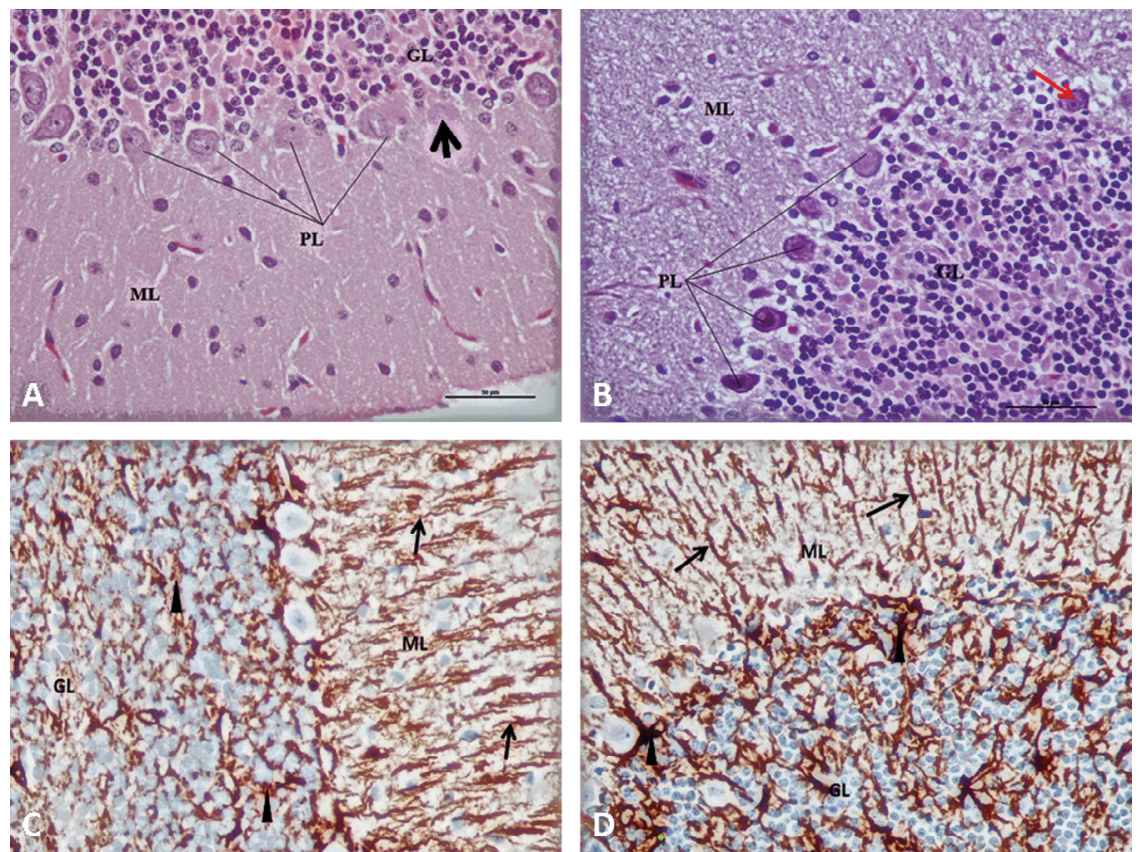

Figure 4. Photomicrographs of the cerebellar cortex from $\mathrm{Pb}$ and garlic treated groups of mother rats showing $(\mathbf{A})$ monolayer arrangement of lightly stained Purkinje cells (PL). Some cells have normal shape while some of them are shrunken $(\rightarrow)$ [L160 + garlic group]; B. Mild disorganisation or the PL cells with some cells appeared shrunken and deeply stained $(\rightarrow)$ [L320 + garlic group]; C. Decreased immunohistochemical GFAP staining of the astrocytes $(\boldsymbol{\nabla})$, which was similar to control group with some positively stained dendrites in the molecular layer $(\mathrm{ML})(\rightarrow)$ [L160 + garlic group]; D. Less decreased immunohistochemical GFAP staining of the astrocytes ( $\boldsymbol{\nabla})$ with more positively stained branching dendrites in the ML $(\rightarrow)$ [L320 + garlic group]. A, B: haematoxylin-eosin (H\&E) $\times 400 ; C, D: G F A P \times 400$.
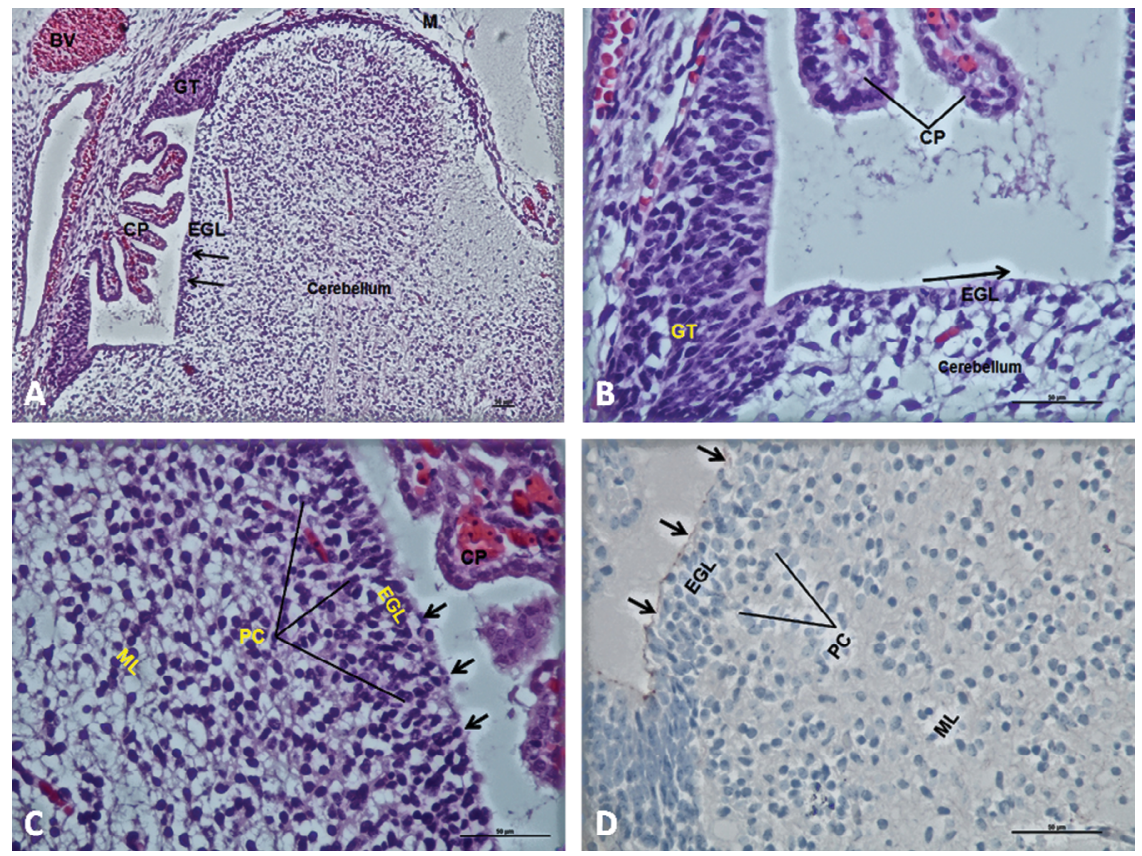

Figure 5. Photomicrographs of the foetal brain in the region of the primitive cerebellum from control foetuses at GD20 showing (A) normal appearance of the foetal cerebellum; the edge of the migrating external granular layer (EGL) from the germinal trigone (GT) is marked by arrows; B. The spread of the EGL ( $\uparrow$ ) from the germinal trigone (GT) of the primitive cerebellum; C. Spindle-shaped, apparently young Purkinje cells (PC). The EGL is formed of oval or rounded cells with darkly stained nuclei and densely aggregated in superficial zone and less packed deep zone; D. Negative or very few and weak GFAP positive cellular reaction $(\uparrow)$, which are scattered in the superficial layers of the external granular (EGL); $\mathrm{M}$ - meningeal layer; $\mathrm{CP}$ — choroid plexus; BP — blood vessels; $\mathrm{ML}$ — molecular layer. Haematoxylin-eosin $(\mathrm{H} \& \mathrm{E}), \mathrm{A}: \times 100$, B, C: $\times 400 ;$ D: GFAP $\times 400$. 

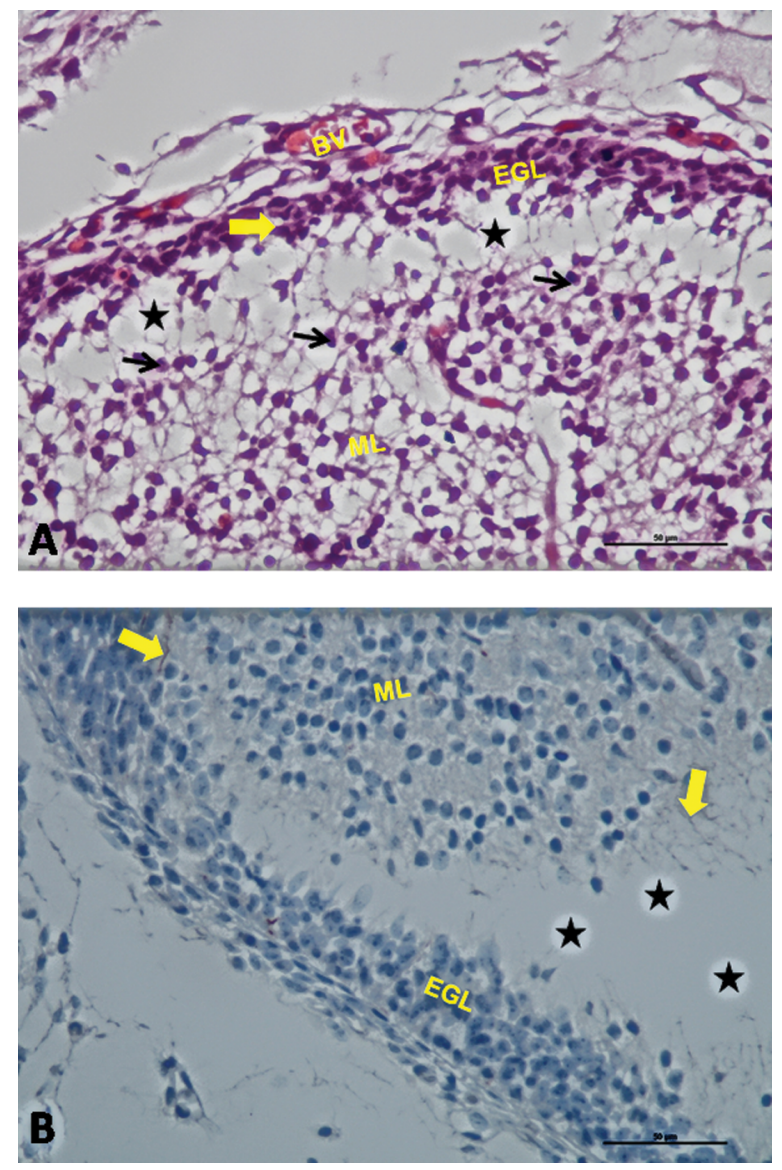

Figure 6. Photomicrographs of the foetal brain in the region of the primitive cerebellum from $\mathrm{Pb}$ treated groups at GD20 showing (A) dispersion of its layers with the presence of cavitations and extracellular oedema $\left(^{*}\right)$. Note that the external granular layer $(\mathrm{EGL})$ is thin in comparison to the control and that its cells are small with deeply stained nuclei. Also, the Purkinje cells showed degeneration and loss of the architecture, with diffusely distributed cells, which failed to establish the typical monolayer and few of them were shrunken and deeply stained ( $\uparrow$ ) [L320 group]; B. Presence of GFAP positive reaction $(\uparrow)$, which are more as compared to control group [L320 group]. A: haematoxylin-eosin $(H \& E) \times 400$, B: GFAP $\times 400$; $\mathrm{ML}$ - molecular layer; BV — blood vessel.

reactive oxygen species in the CNS [33]. Another study described that allicin alters the GFAP content in various brain regions and has a principal neuroprotective influence in minimising neuroglia injury in the CNS [9]; in such a basis, the usage of garlic in the current study diminished GFAP expression in rats' cerebellum.

In the recent decades, a greater attention has been paid to the herbal medicine even in well developed countries due to their few side effects and lower costs [20]. A number of clinical studies have suggested that the antioxidants in fruits and vegetable are key factors in reducing the incidence of many chronic diseases [29]. Garlic is a medicinal plant that
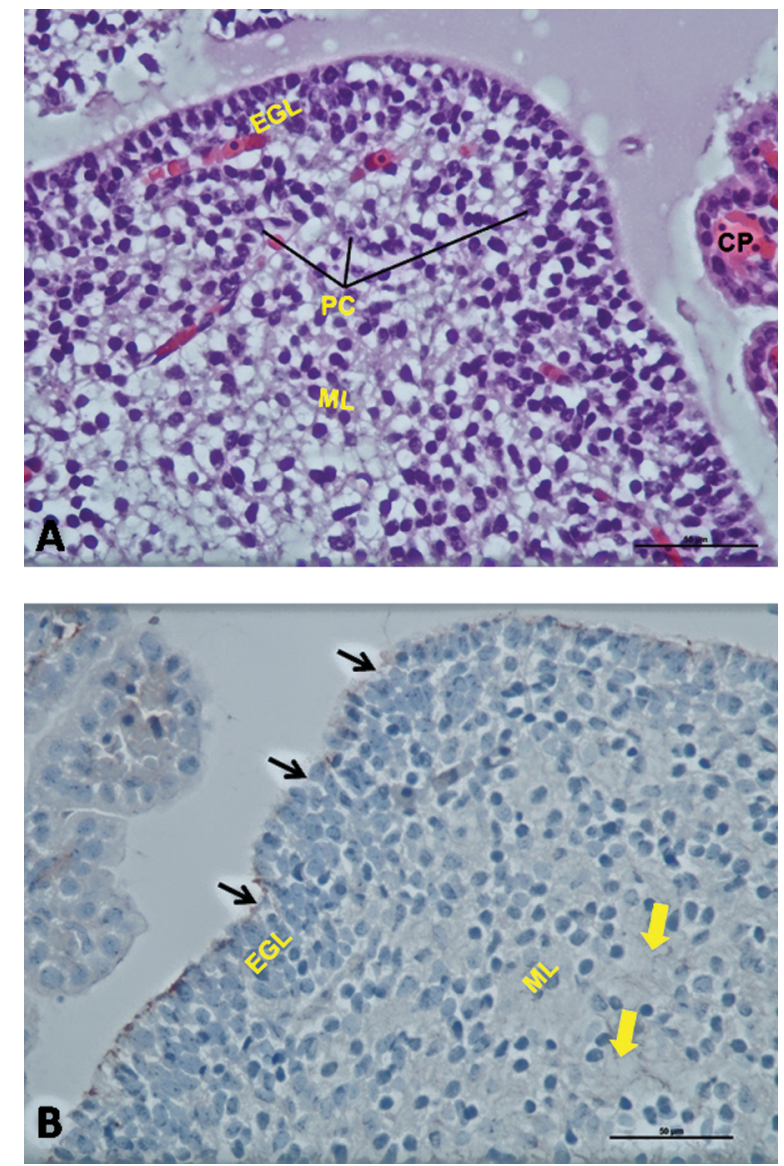

Figure 7. Photomicrographs of the foetal brain in the region of the primitive cerebellum from $\mathrm{Pb}$ and garlic treated rats at GD20 showing (A) a picture similar to that in the control foetuses; EGL - external granular layer; $\mathrm{PC}$ - Purkinje cells; $\mathrm{ML}$ - molecular layer $[\mathrm{L} 320+$ garlic group $] ;$ B. A reduction in the number of GFAP immunoreactive astrocytes $(\uparrow)$, which are scattered in the superficial layers of the EGL and ML [L320 + garlic group]. A: haematoxylin$-e 0 \sin (\mathrm{H} \& \mathrm{E}) \times 400$, B: GFAP $\times 400$.

has been ascribed to have outstanding therapeutic properties. Its active agent is allicin, which imparts its characteristic odour as well as medicinal properties. Garlic can prevent oxidative stress by scavenging the reactive oxygen species and enhancing cellular antioxidant enzymes [41].

In the present study, the female rats that were treated with garlic along with $\mathrm{Pb}$-exposure showed improved structural changes of the cerebellar cortex and recovery of Purkinje cells [23]. In accordance, previous studies have reported the ameliorative role of garlic and its role in enhancing elimination of $\mathrm{Pb}$-induced toxicity [24]. Also, it was reported 
the protective effect of garlic against $\mathrm{Pb}$-induced neurotoxicity in rats by improving the levels of various biomarkers of oxidative stress in different regions of the brain [1]. Similarly in this study, garlic co-treatment results in significant increase in antioxidant enzyme activities in the brain of $\mathrm{Pb}$ treated rats, which is in agreement with the report of Valko et al. [43] who reported similar finding after lead treatment [24]. Furthermore in many previous studies, it was stated that the garlic contains sulphur-containing compounds which have prophylactic efficacy in reducing the $\mathrm{Pb}$ burden from variable tissues [28].

\section{Limitations of the study}

The limitations of this study are due to the number of animals that might be larger and the use of two different doses of lead. Also, the use of immunostaining for the morphology of the cerebellum, especially the foetal cerebellum was quite sensitive. More studies are recommended to support the hypothesis of this study. Also, further clinical researches that support the damaging effect of lead will be needed to confirm the observation of the study. Quantitative measures, such as stereology, and immunostains for the morphology of Purkinje cells, such as calbindin D-28k, are recommended to support the hypothesis of the study. Also, clinical studies dealing with motor coordination changes might confirm the findings of the study.

\section{CONCLUSIONS}

In conclusion, this study demonstrated the unsafe effects of $\mathrm{Pb}$ exposure in our daily life in general and during pregnancy in particular and the assessment of the developmental toxicity and neurotoxicity in foetuses' due to maternal $\mathrm{Pb}$ exposure, which is dosedependent. This also suggests the easy metal transfer through the placenta which results in toxic $\mathrm{Pb}$ levels in the developing foetal brain. Clinically speaking, this study was important to demonstrate the beneficial role of some natural antioxidant agents such as garlic in protection against heavy metal toxicities.

\section{Acknowledgements}

This project was funded by the Deanship of Scientific Research (DSR), King Abdulaziz University, Jeddah, under grant No. (RG/04/32). The authors, therefore, acknowledge with thanks DSR technical and financial support.

\section{REFERENCES}

1. Abd El-Monem DD. The modulating effect of melatonin against the genotoxicity of lead acetate. JOBAZ. 2012; 65(4): 223-231, doi: 10.1016/j.jobaz.2012.07.001.

2. Abdel Moneim AE. Flaxseed oil as a neuroprotective agent on lead acetate-induced monoamineric alterations and neurotoxicity in rats. Biol Trace Elem Res. 2012; 148(3): 363-370, doi: 10.1007/s12011-012-9370-4, indexed in Pubmed: 22395955.

3. Adu EK, Yeboah S. The efficacy of the vaginal plug formation after mating for pregnancy diagnosis, and embyonic resorption in utero in the greater cane rat (Thryonomys swinderianus, Temminck). Trop Anim Health Prod. 2000; 32(1): 1-10, indexed in Pubmed: 10717938.

4. Afifi O, Embaby A. Histological Study on the Protective Role of Ascorbic Acid on Cadmium Induced Cerebral Cortical Neurotoxicity in Adult Male Albino Rats. J Microsc Ultrastruct. 2016; 4(1): 36-45, doi: 10.1016/j. jmau.2015.10.001.

5. Allam A, El-Ghareeb AA, Abdul-Hamid M, et al. Prenatal and perinatal acrylamide disrupts the development of cerebellum in rat: Biochemical and morphological studies. Toxicol Ind Health. 2011; 27(4): 291-306, doi: $10.1177 / 0748233710386412$, indexed in Pubmed: 21310778.

6. Attia M, Ibrahim FA, Nabil GM, et al. Antioxidant effects of ginger (Zingiber officinale Roscoe) against lead acetateinduced hepatotoxicity in rats. Afr J Pharm Pharmacol. 2013; 7(20): 1213-1219, doi: 10.5897/ajpp2013.3465.

7. Baranowska-Bosiacka I, Gutowska I, Marchetti C, et al. Altered energy status of primary cerebellar granule neuronal cultures from rats exposed to lead in the pre- and neonatal period. Toxicology. 2011; 280(1-2): 24-32, doi: 10.1016/j. tox.2010.11.004, indexed in Pubmed: 21108985.

8. Barkur RR, Bairy LK. Histological study on hippocampus, amygdala and cerebellum following low lead exposure during prenatal and postnatal brain development in rats. Toxicol Ind Health. 2016; 32(6): 1052-1063, doi: 10.1177/0748233714545624, indexed in Pubmed: 25147304.

9. Bellé LP, De Bona KS, Abdalla FH, et al. Comparative evaluation of adenosine deaminase activity in cerebral cortex and hippocampus of young and adult rats: effect of garlic extract (Allium sativum L.) on their susceptibility to heavy metal exposure. Basic Clin Pharmacol Toxicol. 2009; 104(5): 408-413, doi: 10.1111/j.1742-7843.2009.00390.x, indexed in Pubmed: 19413661.

10. Bongiorno P, Fratellone P, LoGiudice P. Potential Health Benefits of Garlic (Allium Sativum): A Narrative Review. J Complement Integr Med. 2008; 5(1), doi: 10.2202/15533840.1084.

11. Butler Walker J, Houseman J, Seddon L, et al. Maternal and umbilical cord blood levels of mercury, lead, cadmium, and essential trace elements in Arctic Canada. Environ Res. 2006; 100(3): 295-318, doi: 10.1016/j.envres.2005.05.006, indexed in Pubmed: 16081062.

12. Celiktas O, Kocabas E, Bedir E, et al. Antimicrobial activities of methanol extracts and essential oils of Rosmarinus officinalis, depending on location and seasonal variations. Food Chem. 2007; 100(2): 553-559, doi: 10.1016/j.foodchem.2005.10.011. 
13. Chetty CS, Reddy GR, Murthy KS, et al. Perinatal lead exposure alters the expression of neuronal nitric oxide synthase in rat brain. Int J Toxicol. 2001; 20(3): 113-120, doi: 10.1080/ 109158101317097692 , indexed in Pubmed: 11488553.

14. Cory-Slechta DA, Virgolini MB, Rossi-George A, et al. Lifetime consequences of combined maternal lead and stress. Basic Clin Pharmacol Toxicol. 2008; 102(2): 218227, doi: 10.1111/j.1742-7843.2007.00189.x, indexed in Pubmed: 18226077.

15. Dribben WH, Creeley CE, Farber N. Low-level lead exposure triggers neuronal apoptosis in the developing mouse brain. Neurotoxicol Teratol. 2011; 33(4): 473-480, doi: 10.1016/j. ntt.2011.05.006, indexed in Pubmed: 21640820.

16. Gargouri M, Ghorbel-Koubaa F, Bonenfant-Magné M, et al. Spirulina or dandelion-enriched diet of mothers alleviates lead-induced damages in brain and cerebellum of newborn rats. Food Chem Toxicol. 2012; 50(7): 2303-2310, doi: 10.1016/j.fct.2012.04.003, indexed in Pubmed: 22504531.

17. González A, Pariente JA, Salido GM. Ethanol stimulates ROS generation by mitochondria through $\mathrm{Ca} 2+$ mobilization and increases GFAP content in rat hippocampal astrocytes. Brain Res. 2007; 1178: 28-37, doi: 10.1016/j.brainres.2007.08.040, indexed in Pubmed: 17888892 .

18. Grandjean P, Bellinger D, Bergman A, et al. The faroes statement: human health effects of developmental exposure to chemicals in our environment. Basic Clin Pharmacol Toxicol. 2008; 102(2): 73-75, doi: 10.1111/j.17427843.2007.00114.x, indexed in Pubmed: 18226057.

19. Han JM, Chang BJ, Li TZ, et al. Protective effects of ascorbic acid against lead-induced apoptotic neurodegeneration in the developing rat hippocampus in vivo. Brain Res. 2007; 1185: 68-74, doi: 10.1016/j.brainres.2007.09.044, indexed in Pubmed: 17959157.

20. Hussain Al, Anwar F, Hussain Sherazi ST, et al. Chemical composition, antioxidant and antimicrobial activities of basil (Ocimum basilicum) essential oils depends on seasonal variations. Food Chem. 2008; 108(3): 986-995, doi: 10.1016/j.foodchem.2007.12.010, indexed in Pubmed: 26065762.

21. Hussein AM, Saleh HA, H N M. Effect of sodium selenite and vitamin $\mathrm{E}$ on the renal cortex in rats: an ultrastructure study. Tissue Cell. 2014; 46(3): 170-177, doi: 10.1016/j. tice.2014.03.002, indexed in Pubmed: 24799186.

22. Iciek M, Kwiecień I, Włodek L. Biological properties of garlic and garlic-derived organosulfur compounds. Environ Mol Mutagen. 2009; 50(3): 247-265, doi: 10.1002/ em.20474, indexed in Pubmed: 19253339.

23. Kern JK, Jones AM. Evidence of toxicity, oxidative stress, and neuronal insult in autism. J Toxicol Environ Health B Crit Rev. 2006; 9(6): 485-499, doi: 10.1080/10937400600882079, indexed in Pubmed: 17090484.

24. Khan M, Mostofa M, Jahan MS, et al. Effect of garlic and vitamin B-complex in lead acetate induced toxicities in mice. Bangl J Vet Med. 2009; 6(2), doi: 10.3329/bjvm. v6i2.2337.

25. Kilikdar D, Mukherjee D, Mitra E, et al. Protective effect of aqueous garlic extract against lead-induced hepatic injury in rats. Indian J Exp Biol. 2011; 49(7): 498-510, indexed in Pubmed: 21800501.
26. Liu J, Han D, LiY, et al. Lead affects apoptosis and related gene XIAP and Smac expression in the hippocampus of developing rats. Neurochem Res. 2010; 35(3): 473-479, doi: 10.1007/ s11064-009-0083-9, indexed in Pubmed: 19911273.

27. Lu X, Jin C, Yang J, et al. Prenatal and lactational lead exposure enhanced oxidative stress and altered apoptosis status in offspring rats' hippocampus. Biol Trace Elem Res. 2013; 151(1): 75-84, doi: 10.1007/s12011-012-9531-5, indexed in Pubmed: 23086308.

28. Mabrouk A, Ben Cheikh H. Thymoquinone supplementation ameliorates lead-induced testis function impairment in adult rats. Toxicol Ind Health. 2016; 32(6): 1114-1121, doi: 10.1177/0748233714548474, indexed in Pubmed: 25216800 .

29. Massadeh AM, Al-Safi SA, Momani IF, et al. Garlic (Allium sativum L.) as a potential antidote for cadmium and lead intoxication: cadmium and lead distribution and analysis in different mice organs. Biol Trace Elem Res. 2007; 120(1-3): 227-234, doi: 10.1007/s12011-007-8017-3, indexed in Pubmed: 17916975.

30. Meyer PA, Brown MJ, Falk H. Global approach to reducing lead exposure and poisoning. Mutat Res. 2008; 659(1-2): 166-175, doi: 10.1016/j.mrrev.2008.03.003, indexed in Pubmed: 18436472.

31. Miodovnik A. Environmental neurotoxicants and developing brain. Mt Sinai J Med. 2011; 78(1): 58-77, doi: 10.1002/msj.20237, indexed in Pubmed: 21259263.

32. Mustafa HN, Hegazy GA, Awdan SA, et al. Protective role of CoQ10 or L-carnitine on the integrity of the myocardium in doxorubicin induced toxicity. Tissue Cell. 2017; 49(3): 410-426, doi: 10.1016/j.tice.2017.03.007, indexed in Pubmed: 28410798.

33. Mustafa HN, Hussein AM. Does allicin combined with vitamin B-complex have superior potentials than alpha-tocopherol alone in ameliorating lead acetate-induced Purkinje cell alterations in rats? An immunohistochemical and ultrastructural study. Folia Morphol. 2016; 75(1): 76-86, doi: 10.5603/ FM.a2015.0076, indexed in Pubmed: 26365852.

34. Mustafa HN. The role of curcumin in streptozotocininduced hepatic damage and the trans-differentiation of hepatic stellate cells. Tissue Cell. 2016; 48(2): 81-88, doi: 10.1016/j.tice.2016.02.003, indexed in Pubmed: 26905192.

35. Patrick L. Lead toxicity part II: the role of free radical damage and the use of antioxidants in the pathology and treatment of lead toxicity. Altern Med Rev. 2006; 11(2): 114-127, indexed in Pubmed: 16813461.

36. Pizzol M, Thomsen M, Andersen MS. Long-term human exposure to lead from different media and intake pathways. Sci Total Environ. 2010; 408(22): 5478-5488, doi: 10.1016/j.scitotenv.2010.07.077, indexed in Pubmed: 20797773.

37. Pourjafar M, Aghbolaghi PA, Shakhse-Niaie M. Effect of garlic along with lead acetate administration on lead burden of some tissues in mice. Pak J Biol Sci. 2007; 10(16): 2772-2774, indexed in Pubmed: 19070102.

38. Ronchetti R, van den Hazel P, Schoeters G, et al. Lead neurotoxicity in children: is prenatal exposure more important than postnatal exposure? Acta Paediatr Suppl. 2006; 95(453): 45-49, doi: 10.1080/08035320600886224, indexed in Pubmed: 17000569. 
39. Sanders T, Liu Y, Buchner V, et al. Neurotoxic effects and biomarkers of lead exposure: a review. Rev Environ Health. 2009; 24(1): 15-45, indexed in Pubmed: 19476290.

40. Shahsavani $D$, Baghshani $H$, Alishahi E. Efficacy of allicin in decreasing lead $(\mathrm{Pb})$ accumulation in selected tissues of lead-exposed common carp (Cyprinus carpio). Biol Trace Elem Res. 2011; 142(3): 572-580, doi: 10.1007/s12011010-8801-3, indexed in Pubmed: 20711682.

41. Sharma S, Shrivastava S, Shukla S. Reversal of lead-induced toxicity due to the effect of antioxidants. J Environ Pathol Toxicol Oncol. 2013; 32(2): 177-187, indexed in Pubmed: 24099431.

42. Sharma V, Sharma A, Kansal L. The effect of oral administration of Allium sativum extracts on lead nitrate induced toxicity in male mice. Food Chem Toxicol. 2010; 48(3): 928-936, doi: 10.1016/j.fct.2010.01.002, indexed in Pubmed: 20060875.

43. Valko M, Rhodes CJ, Moncol J, et al. Free radicals, metals and antioxidants in oxidative stress-induced cancer.
Chem Biol Interact. 2006; 160(1): 1-40, doi: 10.1016/j. cbi.2005.12.009, indexed in Pubmed: 16430879.

44. Verina T, Rohde CA, Guilarte TR. Environmental lead exposure during early life alters granule cell neurogenesis and morphology in the hippocampus of young adult rats. Neuroscience. 2007; 145(3): 1037-1047, doi: 10.1016/j.neuroscience.2006.12.040, indexed in Pubmed: 17276012.

45. Villeda-Hernández J, Méndez Armenta M, Barroso-Moguel R, et al. Morphometric analysis of brain lesions in rat fetuses prenatally exposed to low-level lead acetate: correlation with lipid peroxidation. Histol Histopathol. 2006; 21(6): 609-617, doi: 10.14670/HH-21.609, indexed in Pubmed: 16528671.

46. Zhang YM, Liu XZ, Lu $H$, et al. Lipid peroxidation and ultrastructural modifications in brain after perinatal exposure to lead and/or cadmium in rat pups. Biomed Environ Sci. 2009; 22(5): 423-429, doi: 10.1016/S08953988(10)60021-9, indexed in Pubmed: 20163068. 